\title{
Identification of new isolates of Bacillus thuringiensis using rep-PCR products and $\delta$-endotoxin electron microscopy
}

\author{
A.S.G. Lima ${ }^{1}$, A.M.Guidelli ${ }^{2}$, I.L. Abreu ${ }^{2}$ and M.V.F. Lemos ${ }^{2}$ \\ ${ }^{I}$ Departamento de Genética, USP, Campus de Ribeirão Preto. \\ ${ }^{2}$ Departamento de Biologia Aplicada à Agropecuária, UNESP, Jaboticabal, SP, Brazil.
}

\begin{abstract}
PCR has been used to analyze the distribution of REP (Repetitive Extragenic Palindromic) and ERIC (Enterobacterial Repetitive Intergenic Consensus) sequences (rep-PCR) found within the genome of the bacterium Bacillus thuringiensis, with the purpose to analyze the genetic similarities among 56 subspecies samples and 95 field isolates. The PCR products were analyzed by EB-AGE (ethidium bromide-agarose electrophoresis) and then submitted to banding comparisons, based on the Phyllip software algorithm. When the banding similarities were considered for comparison purposes among all the strains, the phylogenic tree patterns varied according to the rep-PCR primers considered, but, from a broader point of view, the ERIC sequences produced better results, which, together with electron microscopy analysis of the released parasporal bodies and colony morphology characteristics, allowed to detect two possible new subspecies of $B$. thuringiensis.
\end{abstract}

Key words: REP, ERIC, crystal protein, parasporal bodies.

Received: April 19, 2002; accepted: May 27, 2002.

\section{Introduction}

Many organisms of the Lepidoptera, Diptera, Coleoptera and Nematoda orders still cause frequent and serious problems to the production of a variety of important crops. Chemical control based on organochlorated compounds, among others, has shown little efficiency due to several factors: the rising of resistant or tolerant organisms; environmental contamination problems, and international restriction of use (Van Rie et al. 1990a,b; Ferré et al. 1991). Due to insect resistance, environmental pollution, and other events, it became a general issue to look for alternative ways of control, such as the use of bioinsecticides, which act based on specific control mechanisms of the major crop pests, without causing biological impact problems similar to those generated by the use of chemical insecticides.

Bacillus thuringiensis is seen as a biological control bacterium that presents several advantages over the use of chemical control agents, since the parasporal bodies released by such bacteria during their growth are highly specific for some of the major agronomical targets (entomopathogenic action) and with no effect on other non-tar-

Send correspondence to Manoel Victor Franco Lemos. Departamento de Biologia Aplicada à Agropecuária, UNESP, Campus de Jaboticabal, 14884-900 Jaboticabal, SP, Brazil. E-mail: mvictor@ fcav.unesp.br. get insects, plants and domestic animals. These entomopathogenic proteins named $\delta$-endotoxins, are produced as protoxins that can be solubilized and activated by the action of alkaline proteases along the sporulation events (Ferré et al. 1991). The activated toxin molecules are found linked to specific sites located on the apical microvilosities of susceptible larvae intestinal cells (Van Rie et al. 1960a,b). After the toxin induction, its molecules are inserted within the cell's plasmatic membrane and by doing so they punch holes in the cell surface, changing the osmotic equilibrium and determining the cell's death (Van Rie et al., 1989).

It is important to look for new B. thuringiensis strains, and great efforts are presently being undertaken by many different research centers. One of the most recent advances in this area is the use of PCR for such purposes (Bravo et al. 1992). This technique has been used for strain identification and for target prevision, without the need to carry out all the tedious and time-consuming bioassays which are, thus allowing faster detection of new Cry protein coding genes (Carozzi et al. 1991). The use of repetitive DNA sequences such as REP and ERIC, also referred to as rep-PCR, for bacterial classification is becoming frequent, and has allowed comparisons of possible genetic similarities among different bacterial genomes (Versalovic et al. 1991; Louws et al. 1994; Selenska-Pobell et al. 1995). 
Since it became important to overcome the growing need to avoid resistance by the insect pests, it was the objective of the present work to analyze 56 subspecies samples and 95 field isolates of $B$. thuringiensis using rep-PCR to compare and identify probable new genes coding for Cry toxins.

\section{Material and Methods}

\section{Bacterial strains}

The 56 B. thuringiensis subspecies used in this work were obtained from the BACILLUS STOCK CENTER of the Ohio State University, Columbus, USA. The 95 field isolates were obtained from various locations throughout the Brazilian territory (States of Alagoas, Amazônia, Bahia, Ceará, Goiás, Minas Gerais, Mato Grosso, Mato Grosso do Sul, Pará, Pernambuco, Piauí, Paraná, Rio Grande do Norte, Roraima, Rio Grande do Sul, Sergipe, São Paulo). All bacterial samples are being kept at the Laboratory of Bacterial Genetics of the Department of Applied Biology of UNESP, Campus of Jaboticabal, Brazil.

\section{Bacterial growth, genomic DNA extraction and PCR conditions}

Both the subspecies and the field isolates were grown on Petri dishes containing Difco Nutrient Agar, at $30^{\circ} \mathrm{C}$ during 12-18 h, before harvesting for experimental purposes. DNA was extracted using Bio-Rad Instagene Matrix (Bio-Rad), following the procedures recommended by the manufacturer.

The amplification reactions were conducted as follows: $0.8 \mu \mathrm{L}$ Taq-polymerase (4U), $0.8 \mu \mathrm{L} \mathrm{MgCl}_{2}(1 \mathrm{mM})$, $0.5 \mu \mathrm{L}$ of dNTPs $(200 \mathrm{mM})$ (Amersham Pharmacia Biotech), $2.0 \mu \mathrm{L} 10 \mathrm{X}$ buffer ( $\mathrm{KCl} 500 \mathrm{mM}, \mathrm{MgCl}_{2} 15 \mathrm{mM}$, and Tris- $\mathrm{HCl} 100 \mathrm{mM}, \mathrm{pH} 9.0), 0.8 \mu \mathrm{L}$ gelatin $(0.001 \%)$, $3.0 \mu \mathrm{L}$ REP primers $(30 \eta \mathrm{g})$ or $2.5 \mu \mathrm{L}$ ERIC primers (25 ๆg) (GIBCO/BRL Custom Primers), $6.0 \mu \mathrm{L}$ genomic DNA (20 ๆg), and Milli Q purified water to complete $20 \mu \mathrm{L}$ of reaction mixture.

The primer sequences (DE-Bruijn, 1992) were the following:

- $\mathrm{REP}_{1}$ R-I (5' - I I I I C g I C g I C A T C I g g C - 3')

- $\mathrm{REP}_{2} \mathrm{I}\left(5^{\prime}\right.$ - I C g I C T T A T C I g g C C T A C - 3')

- $\mathrm{ERIC}_{1} \mathrm{R}\left(5^{\prime}\right.$ - A T g T A A g C T C C T g g g g A T T C A C - 3') C g - 3')

- $\mathrm{ERIC}_{2}\left(5^{\prime}\right.$ - A A g T A A g T g A C T g g g g T g A g

The amplifications were carried out in a MJ Res model PTC 100 thermocycler, using the following program for REP primers: $1 \mathrm{~min}$ at $94{ }^{\circ} \mathrm{C}, 1 \mathrm{~min}$ at $45^{\circ} \mathrm{C}$, and $2 \mathrm{~min}$ at $72{ }^{\circ} \mathrm{C}$, 41 cycles with a final temperature of $20^{\circ} \mathrm{C}$. For the ERIC primers, the program was: $1 \mathrm{~min}$ at $94{ }^{\circ} \mathrm{C}, 1 \mathrm{~min}$ at $50^{\circ} \mathrm{C}$, and 2 min at $72{ }^{\circ} \mathrm{C}, 41$ cycles with a final temperature of $20^{\circ} \mathrm{C}$.

\section{Analysis of PCR products}

$2 \mu \mathrm{L}$ of loading dye were added to the amplified samples, and $11 \mu \mathrm{L}$ of each sample were submitted to EB-AGE (1.5\% gel) (Sambrook et al. 1989). Electrophoresis was performed in HORIZON 58 and 11-14 chambers (GIBCO/BRL), using TEB $1 \mathrm{X}$ as running buffer (Tris- $\mathrm{HCl}$ $890 \mathrm{mM}$, EDTA, $25 \mathrm{mM}$, and $\mathrm{H}_{3} \mathrm{BO}_{3} 890 \mathrm{mM}$, pH 8.2), at $72 \mathrm{~V}$ during $2-3 \mathrm{~h}$. The amplification products were analyzed under UV transillumination, and filed using a Bio-Rad GEL-DOC 2000 photodocumentor device.

\section{Phylogenetic analysis}

The amplification products were transformed into binary bidimentional matrixes and submitted to the Phylip software algorithm (Phylogeny Inference Package, release 3.6a2.1; http://evolution.genetics.washington.edu/phylip. html).

\section{Identification of parasporal bodies in the field isolates}

After a long incubation period on Nutrient Agar plates, all the 95 field isolates were examined under optical microscopy $(1,000 \mathrm{X})$, for parasporal body morphology analysis (Smirnoff, 1962). The parasporal bodies produced by field isolates $\mathrm{PI}_{2}$ and $\mathrm{SP}_{6}$ were purified, lyophilized, observed under electron microscopy (JEOL Scan Electron Microscope of the UNESP/Jaboticabal Electron Microscopy laboratory) and photographed using ILFORD FP4-125 black-and-white film, processed according to the manufacturer's instructions. Afterwards, the parasporal bodies were grouped according to their morphology.

\section{Results and Discussion}

\section{REP primers}

Figure 1A shows the amplified material from the field isolates, when REP primers were used. Based on an overall view, most of the isolates seemed to show a common amplification pattern, with only two samples not sharing this homology. These samples correspond to the field isolates $\mathrm{PI}_{2}$ and $\mathrm{SP}_{6}$, which exhibited different amplification patterns. With regard to the $B$. thuringiensis subspecies, it was observed that most of the amplification products of the fifty-six samples used in this work had the same patterns as those of the field isolates. For a group of fourteen subspecies strains, however, it was not possible to detect any amplification product (data not shown). 
Figure 1B shows a comparative analysis based on PCR-amplified fragment bands observed on the electropherograms of the 56 subspecies, compared to the 95 field

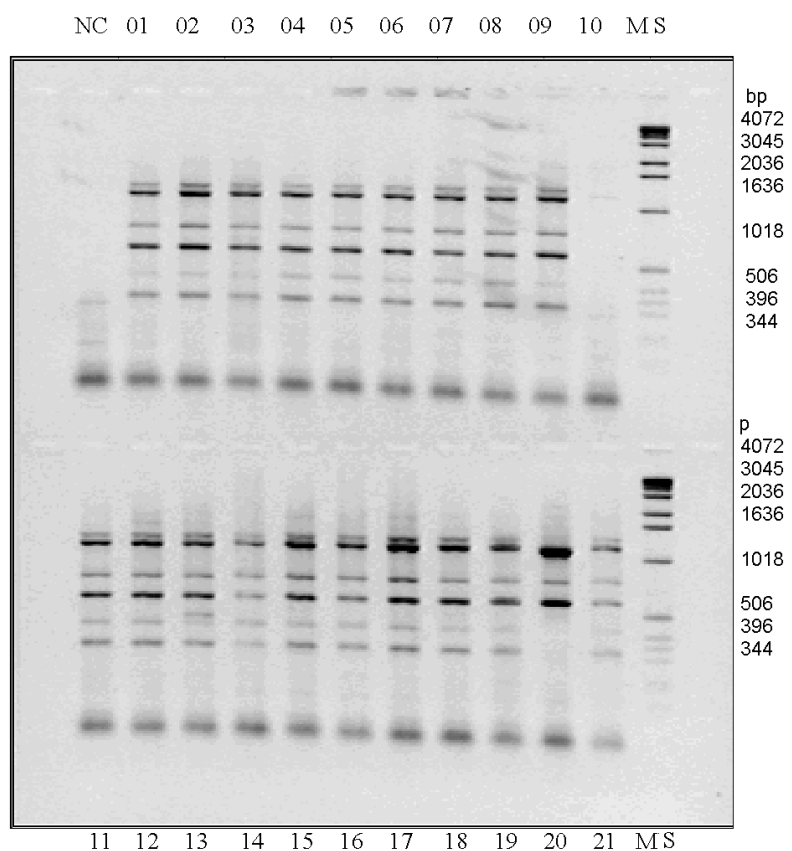

Figure 1A - Electropherogram of PCR products obtained from the amplification of some DNA samples in the presence of primers REP1-R and REP2. Samples 10 and 20 correspond to $\mathrm{PI}_{2}$ and $\mathrm{SP}_{6} ; \mathrm{NC}=$ negative control; MS = molecular sizes $1 \mathrm{~kb}$.

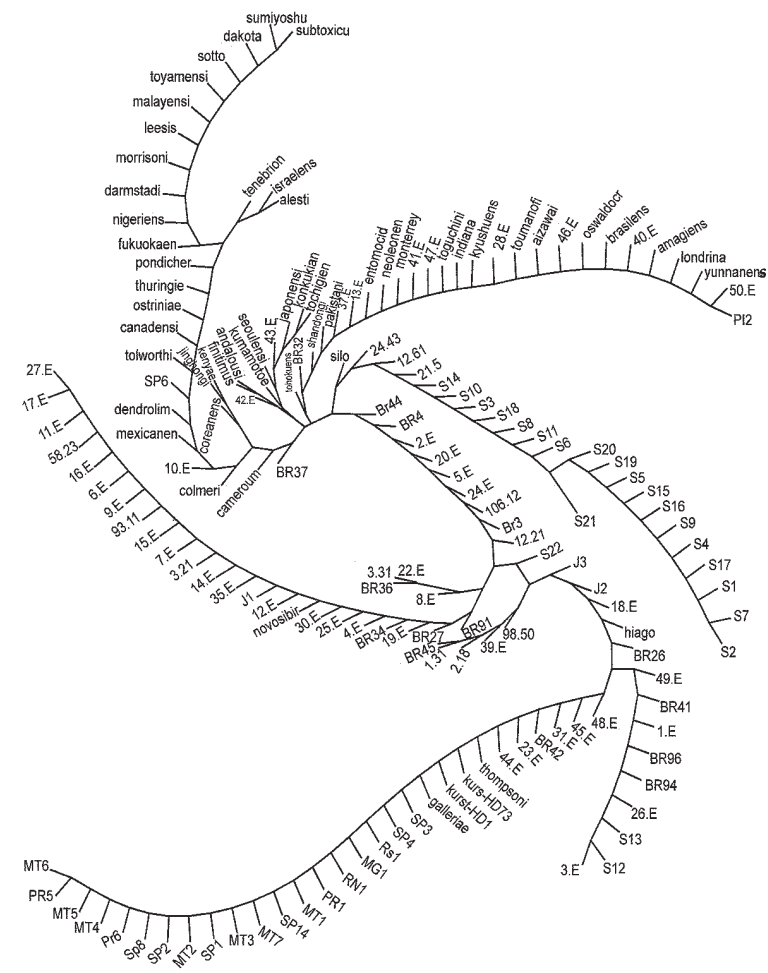

Figure 1B - Dendrogram comparing PCR products of the field isolates and of the standard strains (DNA samples amplified in the presence of primers REP1-R and REP2) isolates; the amplification products were obtained using primers REP1-R and REP2. It can be seen that two clearly separated groups of clustered subspecies and field isolate samples were formed; only a very small amount of crosslinking was observed (comparisons made using Phylip software).

\section{ERIC primers}

Figure 2A shows that, when ERIC primers were used, the banding patterns of most of the field isolates were not as similar as when this comparison was made with the amplification products obtained with REP primers, but the differences between the $\mathrm{PI}_{2}$ and $\mathrm{SP}_{6}$ field isolates and the fifty-six $B$. thuringiensis subspecies were kept.

Figure 2B shows a comparative analysis based on PCR-amplified fragment bands observed on the electropherograms of the 56 subspecies, compared to the 95 field isolates; the amplification products were obtained using ERIC1-R and ERIC2 primers. It also can be seen that two clearly separated groups of clustered subspecies and field isolates samples were formed, only a greater amount of cross-linking was found (comparisons made using Phylip software).

Using these two kinds of conserved bacterial sequences for phylogenetic comparisons according to Versalovic et al. (1994), Louws et al. (1994) and Selenska-Pobell et al. (1995), this work attempted to find out if some information regarding the type of $\delta$-endotoxin produced by the isolated

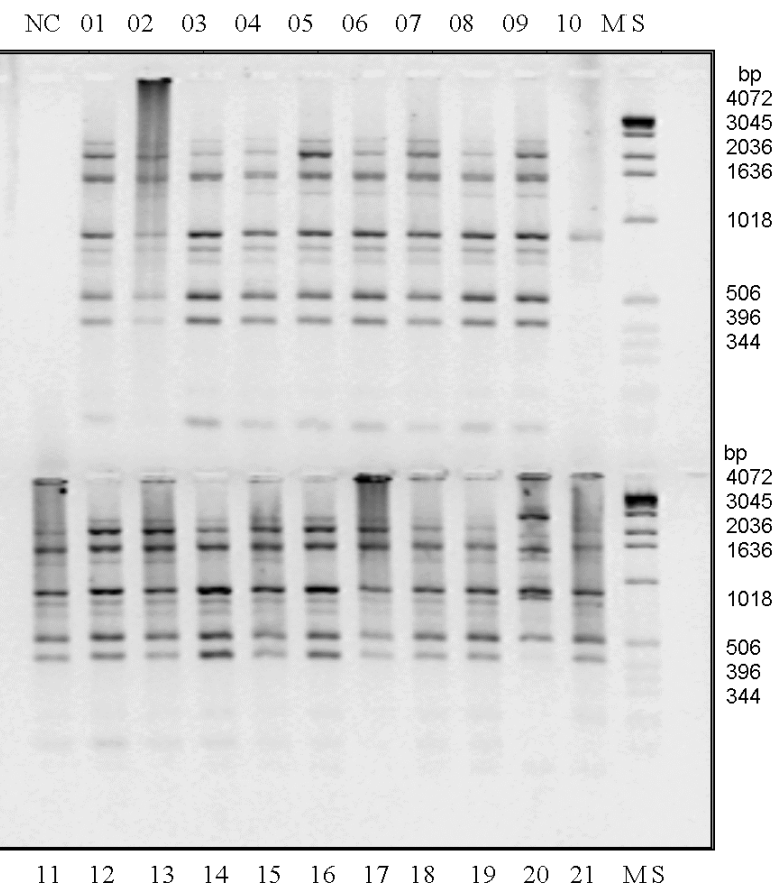

Figure 2A - Electropherogram of PCR products obtained from the amplification of some DNA samples in the presence of primers ERIC1-R and ERIC2. Samples 10 and 20 correspond to $\mathrm{PI}_{2}$ and $\mathrm{SP}_{6} ; \mathrm{NC}=$ negative control; $\mathrm{MS}=$ molecular sizes $1 \mathrm{~kb}$. 


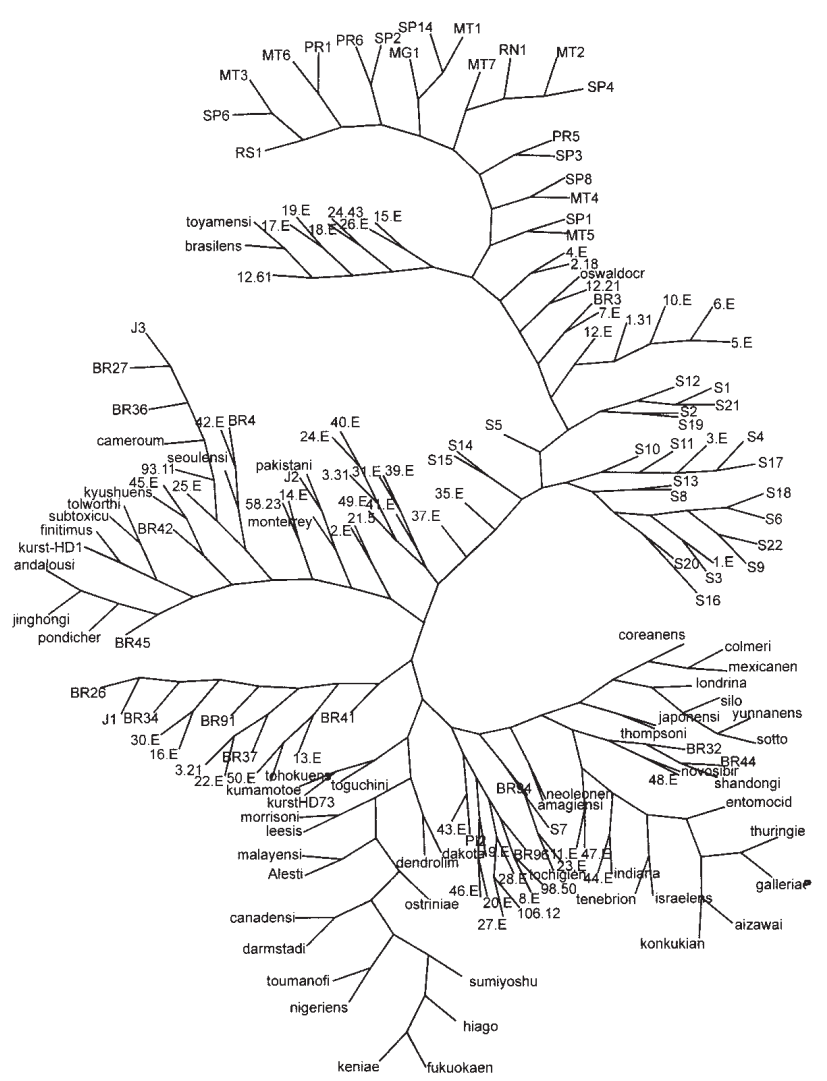

Figure 2B - Dendrogram comparing PCR products of the field isolates and of the standard strains (DNA samples amplified in the presence of primers ERIC1-R and ERIC2).

field samples could be pinpointed using the PCR-amplified material, after the reaction with these types of repetitive sequences. Indeed, a certain degree of cross-linking between the subspecies and the isolated field samples was detected, whether REP or ERIC primers were used, and the field isolates $\mathrm{PI}_{2}$ and $\mathrm{SP}_{6}$ were part of the cross-linked samples, but with different banding patterns. It must be said, however, that from a phylogenetic point of view, the ERIC primers produced a phylogram (Figure 2B) with better spreading, generating a tree that shows more strain differences. This result might be due to the fact that, the ERIC primers being longer, their chances to anneal to their target sequences are greater. Since neither the REP nor the ERIC repetitive sequences have any relation to the types of $\delta$-endotoxin produced by these bacterial strains, we decided to evaluate their types of parasporal bodies, analyzing their shapes and comparing them with the described types.

\section{Colony and parasporal body morphology}

The colony and parasporal body morphology analysis revealed that the field isolates were made of general smooth colonies with an irregular shape, except for isolate $\mathrm{PI}_{2}$ that produced dark yellowish colonies.
When crystal morphology was considered and compared between the subspecies strains and the field isolates, almost all of them were found to produce similar bipiramidal crystals, as did all the subspecies in which the CryI proteins are expressed, such as kurstaki-HD73, aizawai and tolworthi; the exceptions were isolates $\mathrm{PI}_{2}$ and $\mathrm{SP}_{6}$. For these two field isolates $\left(\mathrm{PI}_{2}\right.$ and $\left.\mathrm{SP}_{6}\right)$, the crystal shapes were determined by scanning electron microscopy, after special crystal purification by an ultracentrifugation procedure (Fast, 1972), and can be seen in Figures 3 and 4. In isolate $\mathrm{SP}_{6}$, the common bipiramidal shape was detected, but in $\mathrm{PI}_{2}$ the crystals were amorphous. As far as shape is concerned, the bipiramidal crystals are related to lepidopteran targets, but without a pathogenesis level description. In field isolate $\mathrm{PI}_{2}$, the size of the parasporal bodies ( 0.4 to $0.5 \mu \mathrm{m})$ was considered quite small.

Based on the above mentioned differences among the bacterial samples analyzed in this study, we propose that field isolates $\mathrm{PI}_{2}$ and $\mathrm{SP}_{6}$ might correspond to new $B$. thuringiensis strains. Further studies of their $\delta$-endotoxin specificity and mode of action need to be carried out in the future.

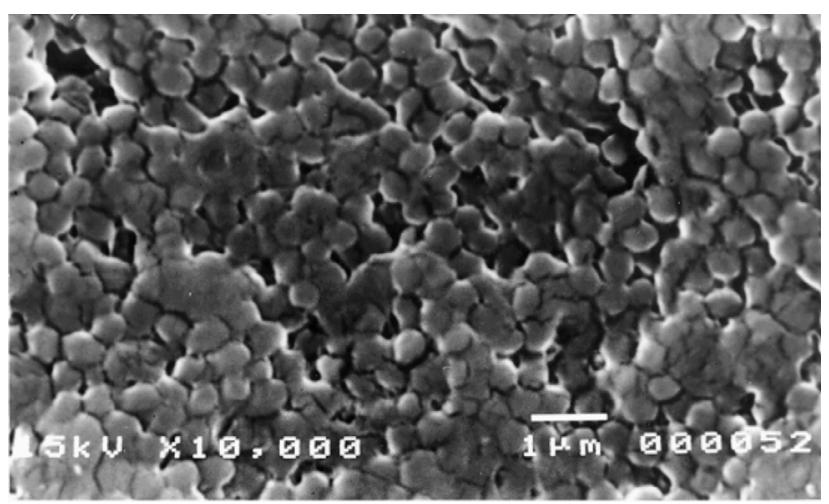

Figure 3 - Electron scanning photography of the amorphous parasporal bodies produced by field isolate $\mathrm{PI}_{2}$.

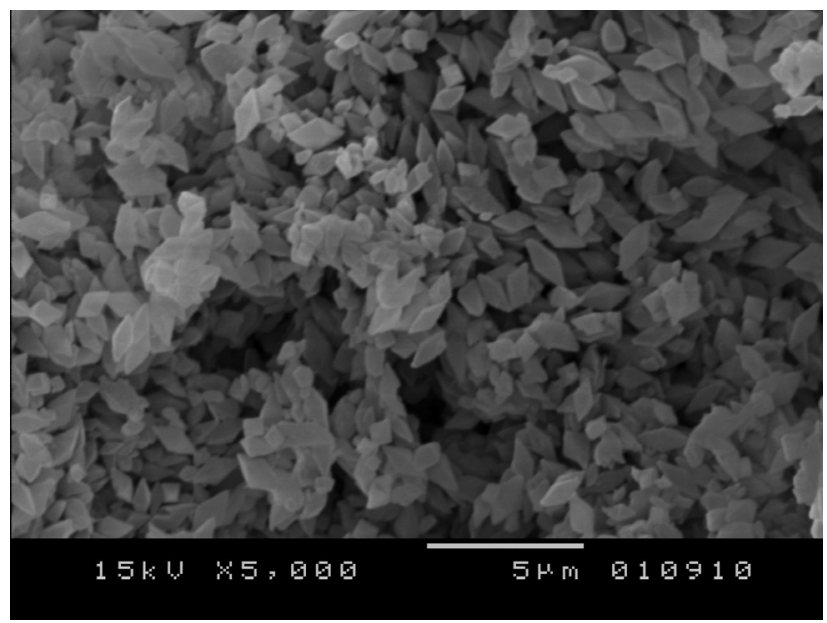

Figure 4 - Electron scanning photography of the typical bipiramidal parasporal bodies produced by field isolate $\mathrm{SP}_{6}$. 


\section{Acknowledgments}

The authors would like to thank Dr. Eliana G.M. Lemos for her assistance with critical manuscript reading, and CAPES which supported ASGL with a scholarship.

\section{References}

Bravo A, Haendrickx K, Jansens S. and Peferoen M (1992) Immunocytochemical analysis of specific binding of Bacillus thuringiensis insecticidal crystal proteins to lepidopteran and coleopteran mid-gut membranes. Journal Invertebrate Pathology 60:247-253.

Carozzi NB, Kramer VC, Warren GW, Evola S and Koziel M (1991) Prediction of insecticidal activity Bacillus thuringiensis strain by polymerase chain reaction product profiles. Applied Environmental Microbiology 57:353-356.

DE-Bruijn FJ (1992) Use of repetitive (repetitive extragenic palindromic and enterobacterial repetitive intergenic consesus) sequences and polymerase chain reaction to fingerprint the genomes of Rhizobium meliloti isolates and other soil bacteria. Applied Environmental Microbiology 58(7):2180-2187.

Fast PG (1972) The delta endotoxin of Bacillus thuringiensis III: a rapid method for separating parasporal bodies from spores. Journal of Invertebrate Pathology 20:189-140.

Ferré J, Real MD, Van Rie J, Jansens S and Peferoen M (1991) Resistance to the Bacillus thuringiensis bioinsecticide in a field population of Putella xilostella is due to a change in a mid-gut membrane receptor. Proc. Natl. Acad. Sci. 88:5119-5123.

Louws FJ, Fulbright DW, Stephens CT and DE-Bruijn FJ (1994) Specific genomic fingerprint of phytopathogenic Xanthomonas and Pseudomonas pathovars and strains generated with repetitive sequence and PCR. Applied Environmental Microbiology 60(7):2286-2295.

Sambrook J, Frisch EF and Maniatis T (1989) Molecular cloning: a laboratory manual. $2^{\text {nd }}$ ed., Cold Spring Harbor Laboratory Press, New York.

Selenska-Pobell S, Gigova L and Petrova N (1995) Strain-specific fingerprints of Rhizobium galegae generated by PCR with arbitrary and repetitive primers. Journal of Applied Bacteriology 79:425-431.

Smirnoff WA (1962) A staining method for differentiating spores, crystal and cell of Bacillus thuringiensis (berliner). Journal of Insect Pathology 4:384-386.

Van Rie J, Jansens S, Hofte H, Degheele D and Mallaert HV (1989) Specificity of Bacillus thuringiensis delta-endotoxins: importance of specific receptors on the brush border membrane of the mid-gut of target insects. European Journal Biochemistry 186:239-247.

Van Rie J, Jansens S, Hofte H, Degheele D and Mellaert HV (1990a) Receptors on the brush border membrane of the insects' mid-gut as determinants of the specificity of Bacillus thuringiensis $\delta$-endotoxins. Applied Environmental Microbiology 56(5):1378-1385.

Van Rie J, MacGaughey WH, Johnson DE, Barnett BD and Mallaert HV (1990b) Mechanism of insect resistance to the microbial insecticide Bacillus thuringiensis. Science 247:72-74.

Versalovic J, Koeuth T and Lupski JR (1991) Distribution of repetitive DNA sequences in eubacteria and application to fingerprinting of bacterial genomes. Nucleic Acids Research 19(24):6823-6831.

Versalovic J, Schneider M, DE-Bruijn FJ and Lupski JR (1994) Genomic Fingerprint of Bacteria Using repetitive Sequence-Based Polimerase Chain Reaction. Methods in Molecular and Cellular Biology 5:25-40. 